Revista lus et Praxis, Año 17, No 1, 2011, pp. 205 - 230

ISSN 0717 - 2877

Universidad de Talca - Facultad de Ciencias Jurídicas y Sociales

"El recurso de apelación sobre los alimentos provisorios dictaminados en audiencia de proceso de alimentos"

Eduardo Gandulfo Ramírez

\title{
EL RECURSO DE APELACIÓN SOBRE LOS ALIMENTOS PROVISORIOS DICTAMINADOS EN AUDIENCIA DE PROCESO DE ALIMENTOS*
}

\author{
THE APPEAL RESOURCE OVER PROVISIONAL \\ ALIMONY SENTENCED IN AN ALIMONY PROCEDURE HEARING
}

Eduardo Gandulfo Ramírez

\begin{abstract}
RESUMEN
El artículo presenta un examen acerca de la procedencia del recurso de apelación, respecto de la resolución que resuelve sobre los alimentos provisorios, que han sido dictados en audiencia, en el específico caso del proceso de alimentos. Dos aspectos son los que se abordan: i) si es admisible la presentación de la apelación y ii) la modalidad de interposición para que sea procedente el recurso. En el proceso de solución metodológica de los problemas analizados, se observarán fuertes aspectos del contexto de la Codificación.

ABSTRACT

This paper presents a review on the admissibility of the appeal, on the resolution which rules on temporary child support that have been dictated in open court, in the specific case of child support procedure. Two aspects are addressed: i) if permitted the filing of the appeal and ii) how to present the appeal. In the process of finding a methodological solution in the adressed issues, we will see strong aspects of Codification context.
\end{abstract}

PALABRAS CLAVE

Recurso de Apelación, Alimentos Provisorios, Medida Cautelar Anticipatoria KEYS WORD Appeal, Temporary Child Support, Precautionary Measure

\section{INTRODUCCIÓN}

La construcción de los nuevos procesos orales no ha estado, en caso alguno, exenta de problemas. Para nosotros, que nos encontramos en los primeros

\footnotetext{
*El autor agradece a don Sergio Peña Neira, Carlos Cerda, Felipe Pulgar, Jorge Rosales y Andrés Peña Adasme, por sus lecturas críticas del presente texto. Trabajo recibido el 7 de marzo y aprobado el 3 de abril de 2011.

${ }^{* *}$ Abogado; Licenciado en la Pontificia Universidad Católica de Valparaíso; Posgraduado de Especialista en Argumentación Jurídica en la Universidad de Alicante; Profesor Universidad Nacional Andrés Bello. Correo electrónico: ednega@gmail.com.
} 
estadios de las construcciones orales, frente a las largas tradiciones de otros países, resulta particularmente compleja la adaptación de la idea de oralidad en el esquema de la Codificación. En efecto, se trata de un proceso mental y práctico fuertemente tentativo, con las graves consecuencias que ello trae aparejado para la certeza y seguridad jurídica de los ciudadanos sujetos a los resultados de la jurisdicción oral. El problema se agrava cuando los operarios jurídicos muestran carencias argumentativo-jurídicas y desconocimientos de los cánones propios del Derecho de la Codificación, cuestiones claves para la correcta aplicación del Derecho en tiempo de reformas. Particular relevancia cobra el conocimiento de la idea de Codificación, pues las reformas orales se construyen y se insertan, justamente, en el marco del Derecho codificado.

Uno de los temas más complejos, en donde están en juego dichas cuestiones, es el del recurso de apelación respecto a las resoluciones relativas a los alimentos provisorios, a causa de que la producción legislativa exhibe una falta de rigor, en términos de Codificación, respecto a la construcción normativa, tanto de lo que dictamina como de lo que suprime, lo que vuelve compleja la comprensión de las soluciones correctas ${ }^{1}$.

El presente ensayo tiene por objeto, precisamente, pasar revista sobre dos tópicos: i. Si es procedente el recurso de apelación en contra de una resolución que se pronuncia sobre los alimentos provisorios, y ii. Sobre la forma en que sea procedente.

\section{Procedencia del recurso de apelación respecto a LOS ALIMENTOS PROVISORIOS DICTADOS EN AUDIENCIA}

La procedencia del recurso de apelación en contra de resoluciones relativas a esta materia, puede referirse indistintamente tanto como si los alimentos provisorios han sido decretados, como si han sido rechazados o si han sido rebajados o aumentados.

\section{La tesis que niega la apelación}

Una posición señala que no es procedente el recurso de apelación, con respecto a los alimentos provisorios, basado en un argumento de texto aislado: el Art. 26 de la Ley de Tribunales de Familia (LTF).

\footnotetext{
${ }^{1}$ Obsérvese que la Corte de Apelaciones de La Serena, haciendo correcto uso de la facultad del Art. $5^{\circ}$ CC, en el oficio 56-2009, de 13 de enero de 2009, y luego en el oficio $N^{\circ}$ 46-2010, de 13 de enero de 2010, ha denunciado al legislador exactamente el mismo problema: cómo procede la apelación respecto a los alimentos provisorios dictados en audiencia. Ambos en: http://www.poderjudicial. cl/PDF/Prensa_Com/CuentaPublica/discurso2009/5-laserena-2009.pdf y http://www.poderjudicial.cl/ PDF/Prensa_Com/CuentaPublica/discurso2010/5_5_La_Serena.pdf [visitado el 04/02/2011].
} 
En efecto, aquel texto norma, regulando los incidentes en el proceso oral, que respecto de la resolución de las incidencias en las audiencias no procederá recurso alguno. Lo que viene corroborado por la propia oración normativa que señala: "Los incidentes serán promovidos durante el transcurso de las audiencias en que se originen y se resolverán inmediatamente por el tribunal, previo debate... Las decisiones que recayeren sobre estos incidentes no serán susceptibles de recurso alguno".

Ahora bien, dado que los alimentos provisorios son cuestiones accesorias al proceso principal-con tramitación especial-, donde se decide, precisamente, de manera provisoria sobre el objeto principal y final del pleito, los alimentos $^{2}$, sin perjuicio de lo que ocurra en definitiva luego de tramitado el proceso principal, su discusión tiene el carácter de incidencia, por lo que en principio estaría sometido a la regla de prohibición de recursividad.

A lo anterior debe sumarse que el artículo es claro y en principio completo, pues regula sin ambages la clase misma de los incidentes, es decir, el todo, sin tener en principio otras normas que actúen como requisitos para su configuración.

\section{La tesis que admite la apelación}

La otra posición señala que sí es procedente el recurso de apelación respecto de la resolución que se pronuncia sobre los alimentos provisorios.

En primer lugar, el Art. 26 LTF no se trata de una norma completa y autónoma, estrictamente hablando. En efecto, sabemos hace bastante tiempo que las normas pertenecen a un tejido discursivo en el Derecho de la Codificación, en donde un artículo se encuentra inmerso en una red de enunciados normativos, construidos desde principios, con la pretensión de ser desarrollados sistemáticamente (sin perjuicio de los errores o especificaciones que se puedan contener); todo ello, de la mano de la teoría jurídica. De esta manera, los contenidos normativos,

${ }^{2}$ Es decir, no decide el objeto principal del pleito, sino sobre lo que será posteriormente la decisión final del pleito. Según J. Salas Vivaldi, de acuerdo a la vieja legislación de la Ley 16.618, la cuestión de la procedencia de los alimentos provisorios constituye un incidente del pleito (SALAS VIVALDI, J., Los Incidentes y en Especial el de la Nulidad Procesal, Edit. Jurídica de Chile, Santiago, 1989, p. 245). De hecho, el tratamiento se mantiene incluso con la Ley 19.741, de 5 julio de 2001, cuando dispuso para el inciso final del antiguo Art. $5^{\circ}$ LPA que: "La solicitud [de alimentos provisorios] correspondiente se tramitará como incidente". Es menester señalar que, como indica C. Anabalón Sanderson, la ley chilena ha definido los incidentes en términos muy amplios para efectos procedimentales o de tramitación, tratando las cuestiones accesorias "como incidente" (ANABAlón SANDERSON, C., Tratado Práctico de Derecho Procesal Civil Chileno, Ediciones de la Universidad de Chile, Santiago, 1946, p. 186). En tal dirección, entonces, se puede ver la distinción entre cuestiones incidentales -puntos litigiosos- e incidentes - procedimentales- (vid. SaAvedra Gallo, P., "Reflexiones sobre los Incidentes en el Proceso Declarativo", Boletín de la Facultad de Derecho de la UNED No 1, 1992, pp. 187 y 188, y J. MONTERO Aroca, "Síntesis de Derecho Procesal Civil Español", Boletín Mexicano de Derecho Comparado № 89, 1997, pp. 694 y ss.). 
discursivamente, son dependientes de esquemas conceptuales, incluso ajenos o lejanos, pero interconectados.

En el caso del Art. 26 LTF, se requiere para su aplicación del concepto de incidente, que viene trabajado legislativamente desde el Código de Procedimiento Civil. Porque si no fuese así, la pregunta que cabría hacer, es ¿con qué concepto de incidente trabajaríamos, en línea de Codificación?, es decir, en el sentido de conceptos sistemáticamente utilizados, en amplias áreas de materias, para ser utilizadas de manera relativamente uniforme. Lo anterior tiene mayor apoyo si consideramos que, precisamente, la referencia a los incidentes viene en alusión o presuposición del Art. 82 CPC, que señala: "Toda cuestión accesoria de un juicio que requiera pronunciamiento especial con audiencia de las partes, se tramitará como incidente y se sujetará a las reglas de este Título, si no tiene señalada por la ley una tramitación especial", lo que es concordante con lo dispuesto por el Art. 27 LTF, en orden a que el CPC se aplica de manera supletoria a la Ley de Tribunales de Familia, pues ello no sólo ocurre en términos de las figuras de que carezca eventualmente la mencionada ley, sino que al cuerpo teórico procesal volcado sobre el CPC, que pretende delinear de la mayor manera posible la construcción de los diversos tipos de proceso en general. En tal sentido, también el CPC delinea conceptualmente, a través de sus macrofiguras, vastos campos de la legislación procesal. Con mayor razón cuando estamos tratando de una ley especial que no puede contar, en términos de Codificación, con toda una construcción completa (o relativamente) sobre las reglas procedimentales aplicables a toda la realidad procesal. Dicha función la cumplen los códigos base. Lo expuesto cuenta con una limitación: que el esquema conceptual contenido en el discurso base, del tipo supletorio, no se oponga en un determinado campo, a los principios orientadores de la normativa especial oral, como lo indica el propio Art. 27 LTF, que no es el caso cuando estamos definiendo los incidentes, los cuales están conceptualizados de manera suficientemente amplia como para abarcar un incidente en un proceso escrito como en uno oral ${ }^{3}$.

En segundo lugar, si se revisa tanto la Ley de Tribunales de Familia como la Ley de Pensiones Alimenticias (LPA), sí pueden encontrarse normas que nos conecten de mejor manera con el incidente de alimentos provisorios. La impor-

\footnotetext{
${ }^{3}$ Sin embargo, es necesario precisar que no es claro que las cautelares y los alimentos provisorios sean en sí mismos un incidente. Ello, porque si bien la construcción del Art. 82 CPC es muy amplia, la teoría procesal la ha restringido, a un problema procesal que atañe a la marcha del proceso (ROSENBERG, L., Derecho Procesal Civil, T. I, Traducción de A. Romera, E. Carlos, E Krotoschin, EJEA, Buenos Aires, 1955, p. 319), dado que si no se nos escurrirían dentro de los incidentes cuestiones con tramitación incidental de fondo, tales como las tercerías, los cobros de ciertos honorarios, etc. (SALAs, Los Incidentes, cit. nota n. 2, p. 42). No obstante, aunque no lo fueran, de todas maneras tienen una tramitación incidental especial, con su traslado para oponerse, su eventual prueba y decisión especial.
} 
tancia o gravedad de este especial incidente lleva a que tanto la LPA y la LTF se pronuncien sobre ello. En efecto, la LTF señala expresamente en el Art. 67, regulando los recursos, en su numeral $2^{\circ}$, que la apelación será procedente en tres casos, uno de los cuales, que abarca en su extensión, es el de los alimentos provisorios, según veremos. El mencionado Art. 67 № 2 LTF dispone: "Sólo serán apelables la sentencia definitiva de primera instancia, las resoluciones que ponen término al procedimiento o hacen imposible su continuación, y las que se pronuncien sobre medidas cautelares".

La relación de conexión se produce porque la apelación procede expresamente respecto de las resoluciones que se pronuncien sobre el tema de las medidas cautelares. En términos de significado, el artículo es bastante claro, sin embargo, la cuestión deviene en torno a la subclase de casos que abarca: ison los alimentos provisorios una clase de medida cautelar? El Art. 290 CPC regula lo que Ilamamos "medidas precautorias" o actualmente cautelares, señalando, muy escuetamente, que tienen por objeto asegurar el resultado de la acción, sea de manera directa o indirecta. En tal sentido y de manera más precisa, F. CARNELUTTı señala que el "buen fin del proceso (definitivo) depende de dos órdenes de condiciones: que el oficio pueda disponer de los medios necesarios (pruebas y bienes...), o que al final exista una situación de hecho que pueda equipararse a la relación jurídica declarada o constituida cierta por el juez" ${ }^{4}$; entonces, sea directamente o indirectamente, la medida cautelar sirve o se instrumentaliza al resultado de la acción misma, que es lo que pretende expresar en términos muy amplios la ley del Art. 290 CPC, cuando norma: "Para asegurar el resultado de la acción...", a lo que se agregan los dos requisitos del periculum in mora y el fumus bonni iuris, muy bien expresados en el Art. 22 LTF.

Dentro de buena parte de la teoría procesal más clásica que poseemos, los alimentos provisorios son calificados como medidas cautelares anticipatorias, que como tales tienden a anticipar el resultado de la pretensión, si fuese acogida para efectos de proteger el fin de la acción (en tal sentido, es técnicamente incorrecto reducir la figura de la medida cautelar a la mera idea de conservación). Como muy bien señalaba P. CALAMANDREI, en su tratado de las cautelares: "La relación de instrumentalización que liga a la providencia cautelar a la providencia principal puede asumir diversas formas, que a mi entender, cabe reducir a cuatro tipos", y agrega en el tercero "las providencias mediante las cuales se decide interinamente, en espera de que a través del proceso ordinario se perfeccione la decisión definitiva, una relación controvertida, de la indecisión de la cual, si ésta perdurase hasta la emanación de la providencia definitiva, podrían derivar a una de las partes daños irreparables... en este tercer grupo, la providencia cautelar consiste precisamente en una dimensión anticipada y

${ }^{4}$ Carnelutti, F., Instituciones del Proceso Civil, V. I, Traducción de Sentís, EJEA, B. Aires, 1959, p. 88. 
provisoria del mérito, destinada a durar hasta el momento en que a esta regulación provisoria de la relación controvertida se sobreponga la regulación de carácter estable", ejemplificándolo así con ciertas providencias temporales en el proceso de separación temporal y en los casos de "las providencias que la autoridad judicial puede dictar 'en caso de urgente necesidad' en materia de alimentos" ${ }^{\prime \prime}$.

Aquel carácter final de los alimentos provisorios como medida cautelar, es el que resalta CARNelUtTI, cuando nos señala que, esta clase de cautelares, "sirve para garantizar la practicidad del proceso definitivo", y agrega, "reflexiónese que el proceso de alimentos, aunque culmine en una sentencia justa, vendría a ser inútil si, mientras la espera, quien los pide hubiera de morir de hambre, y sería idéntica la inutilidad del proceso de reivindicación de una cosa, si durante su curso quien la posee llegara a esconderla o destruirla", en suma, finaliza el autor señalando que la "condena provisional en materia de alimentos... tiende a evitar que la condena definitiva llegue demasiado tarde" ${ }^{\prime 6}$; esto es, que los alimentos provisorios apuntan al periculum in mora. En el mismo sentido, entre nosotros, J.C. MARín agrega un argumento de corte negativo, para distinguir la diferente forma que toma el peligro de la mora en una medida conservatoria y otra anticipatoria, en orden a que, en el proceso de alimentos, "si bien es posible que se dicten medidas urgentes que resguarden el efectivo cumplimiento de la futura e hipotética sentencia condenatoria, v. gr. prohibiendo la celebración de actos y contratos sobre determinados bienes... lo relevante a la hora de fijar los alimentos provisionales es, en definitiva, que el legislador presume, por el carácter urgentísimo que ellos tienen, que el solicitante de los mismos no puede esperar el desarrollo íntegro del juicio para ver satisfecha su pretensión" ${ }^{\prime \prime}$, lo que termina conectándose con el "peligro en la demora que implica la tramitación" del Art. 22 inc. 1 LTF.

Por supuesto, el fumus boni iuris no puede faltar, pues es condición necesaria que exista un fundamento plausible para decretar su procedencia, respecto de cada uno de los requisitos de los mismos: se trata de la "verosimilitud del derecho invocado", Art. 22 inc. 1 LTF. Como señala el Art. 327 inc. 1 CC, podrá "el juez ordenar que se den provisoriamente [los alimentos], desde que en la secuela del juicio se le ofrezca fundamento plausible". Precisando ello, J.C.

\footnotetext{
${ }^{5}$ Para P., Calamandrei, el elemento urgencia y daño son muy importantes, y redundan en el tipo de régimen a que se somete la petición provisional en relación con la ausencia de declaración de certeza (que sí se formaría si se tratase de un "pronunciamiento parcial" previo). (CAlamandrel, P. Introducción al Estudio Sistemático de las Providencias Cautelares, Librería El Foro, trad. Ayerra, B. Aires, 1996, pp. $53,58,59$ y 104 a 108).

${ }^{6}$ Carnelutti, Instituciones, cit. nota n. 4, pp. 88 y 89.

7 Marín, J.C., Las Medidas Cautelares en el Proceso Civil Chileno, Edit. Jurídica de Chile, Santiago, 2004 , p. 452.
} 
MARín señala no es necesario acreditar el supuesto operativo sin que quepan dudas de su procedencia, ya que tal grado de convicción sería propio de la sentencia definitiva ${ }^{8}$. Con base en dicha exigencia legal, es que la propia ley provea -sólo para el caso de los niños y adolescentes ${ }^{9}$ - de ciertas presunciones para la satisfacción del requisito de medios del alimentante, a efectos de la procedencia de aquellos, de acuerdo al Art. $3 \mathrm{LPA}^{10}$.

Respecto al carácter provisional de las cautelares, éste se ve con claridad en las anticipatorias como los alimentos provisorios, pues más allá de su designación, es la propia ley la que le asigna dicho carácter, en su Art. 327 inc. 1 parte $1^{\text {a }} \mathrm{CC}$, en orden a que "mientras se ventila la obligación de prestar alimentos, deberá el juez ordenar que se den provisoriamente". Por ende, al ser provisorios, la sentencia definitiva siempre los hará cesar, sea que la sentencia fuese en contra o favorable, pues el veredicto principal es un enjuiciamiento original de la pretensión procesal ${ }^{11}$. De ahí que si el fallo es desfavorable procede restituir como regla general: "sin perjuicio de la restitución, si la persona a quien se demanda obtiene sentencia absolutoria" (parte $2^{\mathrm{a}}$ ).

Finalmente, debe considerarse también otra categorización de los alimentos: como medidas cautelares innovativas, en oposición a las conservatorias ${ }^{12}$. Se trata de medidas que tienden a mutar o alterar el estado de hecho de los

\footnotetext{
${ }^{8}$ Marín, Las Medidas, cit. nota n. 7, p. 453 y nota 698.

${ }^{9}$ Es menester tener presente que no es inusual que los operadores jurídicos, por la ritualidad y velocidad del proceso oral, tiendan a confundirse y aplicar las presunciones destinadas a los niños (promulgadas precisamente por su carácter de minoría de edad), a favor de los adultos que piden alimentos.

10 "Para los efectos de decretar los alimentos cuando un menor los solicitare de su padre o madre, se presumirá que el alimentante tiene los medios para otorgarlos" (inc. 1). "En virtud de esta presunción, el monto mínimo de la pensión alimenticia que se decrete a favor de un menor alimentario no podrá ser inferior al cuarenta por ciento del ingreso mínimo remuneracional que corresponda según la edad del alimentante. Tratándose de dos o más menores, dicho monto no podrá ser inferior al $30 \%$ por cada uno de ellos" (inc. 2).

${ }^{11}$ La separación es tajante, y la prueba presentada en la incidencia de los alimentos, no es válida a considerar en el juicio principal, si no se presenta coincidencia probatoria. Así, la Corte de Apelaciones de Valdivia ha señalado, de la pluma del juez D. Carretta Navea: "Que esta Corte no comparte la tesis del apoderado de la parte demandante en orden a que debió considerarse en la sentencia definitiva la prueba ofrecida en los incidentes relativos a alimentos provisorios, por cuanto según el artículo 63 de la ley $N^{\circ} 19.968$ la audiencia de juicio que ha de llevarse a efecto en un solo acto (aun cuando puede prolongarse en sesiones sucesivas si fuere necesario) tiene por objetivo 'recibir la prueba admitida por el tribunal y la decretada por éste, prueba que se rendirá de acuerdo al orden que fijen las partes, comenzando por la del demandante y al final ha de rendirse la ordenada por el tribunal'. La sentencia debe hacerse cargo precisamente de la prueba rendida en el juicio, según lo señala el artículo 66 del mismo cuerpo legal" (caso 'Zúñiga con Dietz', Rol 1007-2008, de 7 de enero de 2009).

${ }^{12}$ J. Montero Aroca tiende a fundir la idea anticipatoria con la innovativa, en Montero, "Síntesis", cit. nota n. 2, p. 775.

Esta clasificación de "innovativa" sostenida por Carnelutti, en Carnelutti, F., Sistema de Derecho Procesal Civil, T. I, Traducción de Alcalá Zamora, UTEHA, B. Aires, 1944, pp. 249 a 251, fue abandonada, no sin
} 
justiciables; en nuestro caso, se busca alterar la situación fáctica inicial de, por ejemplo, el demandado de alimentos, en orden a extraer del patrimonio la suma necesaria para la mantención del actor durante el juicio. En tal sentido, se ajustan a lo dispuesto en el Art. 22 inc. 1 LTF, en cuanto a que el tribunal "podrá decretar las medidas cautelares conservativas o innovativas que estime procedentes".

La ley, por su parte, contiene manifestación expresa sobre la consideración de los alimentos provisorios. Desde el punto de vista lingüístico, la norma legal expresa que los mentados alimentos son considerados como medidas cautelares. En efecto, el Art. 92 LTF norma que: "Medidas cautelares en protección de la víctima. El juez de familia deberá dar protección a la víctima y al grupo familiar. Cautelará, además, su subsistencia económica e integridad patrimonial. Para tal efecto, en el ejercicio de su potestad cautelar y sin perjuicio de otras medidas que estime pertinentes, podrá adoptar una o más de las medidas siguientes:(...) 3. Fijar alimentos provisorios". Sin perjuicio de que este artículo se encuentre en la normativa de la violencia intrafamiliar de la LTF (para la tutela ante ciertos episodios de violencia) y que los alimentos provisorios pueden ser considerados autosatisfactivos ${ }^{13}$, el legislador nos indica una guía o consideración respecto a encuadrar los alimentos provisorios como medidas cautelares.

En igual sentido al que ha sido expuesto, lo ha entendido también la CORTE de Apelaciones de SANtiago, en materia de juicio de alimentos, señalando que: "1 $1^{\circ}$ ) Que de los autos traídos a la cuenta, resulta que la juez recurrida dejó para definitiva el incidente de fojas 127 de dichos autos en que la actora pidió se modifique la modalidad de pago de la pensión de alimentos provisorios regulados. $2^{\circ}$ ) Que atendida la naturaleza precautoria de los alimentos provisorios, esto es, que tienen por objeto adelantar provisoriamente efectos de la sentencia definitiva para evitar perjuicios al actor, no es posible que un incidente relacionado con ellos se resuelva en la misma sentencia definitiva"14.

De las consideraciones técnicas, legales y jurisprudenciales expuestas, podemos concluir que los alimentos provisorios están dentro de la categoría

\footnotetext{
razón, ya en sus Instituciones, cit. nota n. 4, pp. 87 y 88; constatación algo parecida hace CALAMANDREI, P., Introducción, cit. nota n. 5, p. 49, nota 35.

${ }^{13}$ Es necesario tener presente que en el caso de los procesos de reclamación de paternidad (Art. 209 CC), la medida tampoco anticipa la sentencia definitiva, sino que es propiamente autosatisfactiva.

${ }^{14}$ Sentencia de 19 de abril de 1995, dictada en causa Rol 197-95, por los jueces A. Pfeiffer, D. Kokisch y G. Pérez Paredes.

En igual sentido, J.C. Marín, quien señala que "en el ordenamiento jurídico chileno los alimentos provisionales constituyen una clara medida cautelar de fines anticipativos, esto es, aquellas medidas que se pronuncian interinamente sobre la pretensión deducida en juicio (Marín,J.C., Las Medidas, cit. nota n. 7, p. 450).
} 
de las medidas cautelares, a lo menos cuando se trata de los procesos de alimentos ${ }^{15}$.

Si el anterior enunciado es correcto, entonces éste puede ser usado como una premisa en función de apoyo de la conclusión de que los alimentos provisorios -en tanto subclase de medidas cautelares- son apelables, de acuerdo a lo que dispone el Art. $67 \mathrm{~N}^{\circ} 2$ LTF. En relación a lo expuesto, entonces podemos ver que el problema no se trata de una cuestión de claridad en el lenguaje desde el punto de vista del significado de las oraciones involucradas, esto es, la del Art. 26 vs. del Art. $67 N^{\circ} 2$ ambos LTF, sino que se halla en otro nivel, en la extensión del dominio de casos que abarcan las normas.

¿Cuál regulación es la más especial? A mi parecer, ésta es la de los alimentos provisorios. Sucede que la conceptualización de los incidentes como cuestiones accesorias, pero anormales al proceso, es lo suficientemente amplia ${ }^{16}$, como para abarcar cualquier tipo de contenido que suponga medidas cautelares, para efectos de pronunciarnos a favor del Art. 67 LTF y desplazar el Art. 26 LTF. Ahora, miradas las cosas desde el punto de vista del Art. 67 LTF, éste no sólo contempla un caso especial del incidente de medidas cautelares, sino que también abarca el archiconocido caso del incidente de abandono del proceso del Art. 21 LTF, el cual produce el término abrupto del proceso. Por tanto, darle primacía al artículo sobre los incidentes, implica no únicamente dejar sin aplicación, absoluta, de casos a la regla sobre la posibilidad de apelar resoluciones referidas a medidas cautelares, sino también el propio caso específico del incidente de abandono del proceso, que pone término al mismo.

La ratio legis que está tras esto y que determina, además, la conducta legislativa, estriba en la trascendencia, para la vida de los ciudadanos involucrados, del contenido y tipo de las resoluciones seleccionadas. En efecto, si bien el modelo procesal de tipo oral de la audiencia supone ciertas reglas, como lo es la de la concentración -que señala que el proceso debe desenvolverse en una o más audiencias, próximas en el tiempo, sin bifurcaciones hacia otras instancias-, la perfección de cualquier modelo no se mide en términos mera-

\footnotetext{
${ }^{15}$ En contra, Liebman, E., Manual de Derecho Procesal Civil, Ejea, Traducción de Santís,S., B. Aires, 1980, pp. 163 y 164, y entre nosotros, Romero, A., Curso de Derecho Procesal Civil, t. I, Edit. Jurídica de Chile, Santiago, 2006, pp. 43, 62 y 63.

Sin embargo, el mismo A. Romero reconoce situaciones en que sí procede la anticipación como cautelar, en que por la naturaleza del derecho que busca protección, como el de la vida y la integridad física y síquica y otros, pudiendo anticiparse todo el contenido de la decisión de fondo. Respecto de lo cual, puede recordarse lo fundamentado por Carnelutti, en orden a la protección de la manutención de la vida por parte de los alimentos provisorios. La excepción más bien parece tratarse metodológicamente de un contracaso, a la cual podría aplicarse un modus tollens.

${ }^{16}$ Ello es sin perjuicio de reconocer que existen cuestiones que son conceptualmente autónomas al proceso principal, que se ventilan en él mediante el procedimiento incidental, como son las tercerías en el juicio ejecutivo.
} 
mente abstractos sino también pragmáticos, es decir, sobre las consecuencias que éste tenga en la vida de los ciudadanos. De ahí que la construcción del modelo de proceso oral pase por diversas etapas y se trate de una armonización constante de diversos elementos ${ }^{17}$. Precisamente, la entidad o envergadura de la resolución que se recurre, que por su propia naturaleza, de ser una medida cautelar anticipatoria del resultado final del juicio y tutelando las necesidades vitales de los alimentarios (como señalaba CARNELUTTI), y teniendo el potencial de afectar gravemente la sustentación del alimentante (así como del resto de su familia, por ejemplo, de varios hijos menores de edad, en juicio ante los padres del alimentante) ante este título ejecutivo provisional y meramente probable ${ }^{18}$, Ilevó al legislador a establecer la apelación reajustando, expresamente, las piezas del proceso oral (similarmente puede hablarse de la trascendencia que deja a los litigantes sin el acceso a la tutela jurisdiccional). Y obsérvese que esta importancia no sólo la percibe el legislador en materia de recursos en la Ley de Tribunales de Familia, sino que también la concretó en materia de la Ley de Pensiones Alimenticias, estableciendo antaño la regla de la doble instancia, en el Art. $4^{19}$.

En suma, tenemos lo siguiente, si bien el Art. 26 LTF establece que no procederá recurso alguno en contra de las resoluciones pronunciadas en los incidentes, ello tiene excepción en el caso del Art. 67 № 2 LTF. Por tanto, el dominio de casos del Art. 26 queda restringido por el Art. $67 \mathrm{~N}^{\circ} 2$ LTF para los incidentes en que se discutan medidas cautelares en general y el término anticipado del proceso o que se haga imposible su continuación (en lo ideal para la técnica codificadora, debería hacerse una remisión en el Art. 26 al Art. 67 LTF). De lo anterior se concluye que la extensión del Art. 26 LTF no abarca los casos de incidentes de alimentos provisorios, quedando éstos regidos por la normativa del Art. 67 LTF, siendo procedente la apelación de dichos incidentes.

\footnotetext{
${ }_{17}$ Vid. Cappellettı, M., "Valor Actual del Principio de Oralidad", Revista de la Facultad de Derecho de México № 37, 1960, p. 701.

${ }^{18}$ Como señala el Art. 11 LPA: "Toda resolución judicial que fijare una pensión alimenticia... tendrá mérito ejecutivo", respecto de lo cual, resalta J.C. MARín que "en el derecho chileno no se ha cuestionado el hecho de que una providencia tan temprana tenga efectos ejecutivos y pueda, por consiguiente, tener una máxima injerencia en el patrimonio del demandado" (así como en su libertad habría que agregar). MARín, Las Medidas, cit. nota n. 7, p. 453.

19 "La resolución que decrete los alimentos provisorios o la que se pronuncie provisionalmente sobre la solicitud de aumento, rebaja o cese de una pensión alimenticia, será susceptible del recurso de reposición con apelación subsidiaria, la que se concederá en el solo efecto devolutivo y gozará de preferencia para su vista y fallo".
} 


\section{Forma de PROCEDENCIA DEL RECURSO DE APELACIÓN EN CONTRA DE LA RESOLUCIÓN DE INCIDENTES DE ALIMENTOS PROVISORIOS DECRETADOS EN AUDIENCIA}

En este punto podemos notar, especialmente, la existencia de un grave desconocimiento de los operadores jurídicos a la hora de aplicar el Derecho, acerca de la Codificación en términos de objetivos y de su faz de argumentación jurídica, en donde vemos que las distorsiones que introducen los actores del sistema, nos vuelven hacia aspectos rechazables del antiguo régimen precodificador. (Todo ello, sin perjuicio de las negligencias del legislador a la hora de entregar un discurso normativo claro y coherente, sobre cuál es el derecho aplicable a un dominio de casos).

En esta materia se encuentran enfrentadas dos posturas, con desigual mérito entre una y otra: $i$. la que señala que deben presentarse la apelación conjuntamente con la reposición y en subsidio, y ii. señala que puede interponerse de manera separada, pero precediendo reposición ${ }^{20}$.

\section{La apelación debe presentarse conjuntamente y de manera subsidiaria de la reposición}

Usualmente, esta posición realiza una combinación normativa. Ella combina el Art. $4^{\circ}$ inc. 6 LPA con el Art. $67 \mathrm{~N}^{\circ} 2$ LTF, subordinando este último al primero, de tal manera que si no se interpone la reposición conjuntamente con la apelación, en la audiencia ésta no será procedente. Se fija, por arbitrio a la regla de especialidad, que el Art. $4^{\circ}$ LPA dominará la discusión, dado que se trata de una norma vigente y que especialmente se refiere al tema de los alimentos, frente a una norma que regula en general la procedencia de los recursos, como el Art. 67 LTF. Así, el Art. $4^{\circ}$ LPA, en su inc. $6^{\circ}$, dispone: "La resolución que decrete los alimentos provisorios o la que se pronuncie provisionalmente sobre la solicitud de aumento, rebaja o cese de una pensión alimenticia, será susceptible del recurso de reposición con apelación subsidiaria, la que se concederá en el solo efecto devolutivo y gozará de preferencia para su vista y fallo".

Ahora bien, el Art. 67 LTF contiene dos normas pertinentes en la discusión, el numeral 2 y el numeral 3. Sin embargo, el que obtura la aplicación del Art. $4^{\circ}$ LPA es el numeral $3^{\circ}$ del Art. 67 LTF, pues precisamente obliga a presentar la apelación por escrito, lo que hace imposible presentarla oralmente en la audiencia oral, de manera conjunta con la reposición. Frente a tal incompatibilidad, es la regla de especialidad del Art. $4^{\circ}$ inc. 6 LPA la que desplazaría la aplicación del Art. 67 № 3 LTF, perdiendo vigencia en el caso. La conexión

${ }^{20}$ Para una referencia general acerca de la cláusula "en subsidio", vid. Gandulfo, E., "Sobre Preclusiones Procesales en el Derecho Chileno en Tiempo de Reformas", Ius et Praxis Año 15, No 1, 2009, pp. 165 a 178. 
de procedencia, entonces, se realiza directamente con el numeral $2^{\circ}$ del Art. 67 LTF, que concede el recurso de apelación, pero que no indica la forma o modalidad de presentación. Por tanto, la regla sería que, para todo caso que no sea de alimentos provisorios, se procede con apelación escrita, separada de la reposición, pero para los alimentos provisorios la forma sería la reposición oral con apelación oral en subsidio. La solución de conjuntar los recursos en la forma oral, además, tiene como razón de apoyo el ser coherente con el principio de oralidad del Art. 10 LTF.

\section{La apelación debe presentarse de manera separada a la reposición}

2.1. Esta teoría sostiene que la primacía la tiene el Art. $67 \mathrm{~N}^{\circ} 3 \mathrm{LTF}$ por sobre el Art. $4^{\circ}$ inc. 6 LPA, basados en la regla de uniformidad en las soluciones de la Codificación, en la propia regla de especialidad, y en la interpretación holista del Derecho, en particular, del sistema oral.

Lo primero que sostiene es que la regla de especialidad es un canon interpretativo que no tiene un carácter absoluto y puede tener un carácter ambiguo. En cuanto a su relatividad, es posible que, por ejemplo, una norma más especial sea simplemente anterior a otra y que la nueva establezca un régimen general y uniformador diferente; en tal sentido, como dice N. Bоввı, no toda la realización de la justicia legislativa opera hacia la mayor especificación, sino también en dirección hacia una mayor generalización del régimen legal ${ }^{21}$. Por otra parte, el canon de especialidad supone una disposición que regula una clase de casos, y que está en relación con otra norma, la especial, que regula una subclase de casos. El problema que puede ocurrir, deriva de la propia construcción lógica de la teoría de clases, la cual permite construir cuantas clases uno quiera según un criterio meramente convencional, lo que hace que un caso singular pueda ser abarcado, a la vez, por diversas clases de regímenes, y que no sea claro determinar cuál es la regla más especial, pues cada una puja por ella y no se agota una en la otra.

En el presente caso, la regla del inc. 6 Art. 4 LPA fue creada en el contexto de vigencia de los procesos escritos, y para ser aplicada a aquellos tipos de procesos, en virtud de la Ley 19.741, que introdujo la norma como inciso final del Art. 5 de la LPA: "La resolución que decretare los alimentos provisorios o la que se pronunciare provisionalmente sobre la solicitud de aumento, rebaja o cese de una pensión alimenticia, será susceptible del recurso de reposición con apelación subsidiaria, la que se concederá en el solo efecto devolutivo y gozará de preferencia para su vista y fallo". Sólo posteriormente se traslada el contenido del Art. 5 al actual Art. 4 LPA. De hecho, en la última modificación, de

${ }^{21}$ Vid. N. BoвbıO, "Sobre los Criterios para Resolver Antinomias", en Contribuciones a la Teoría del Derecho, Traducción de Ruiz Miguel, A., Madrid, Edit. Debate, 1990, pp. 349 y 350. 
9 de enero de 2007, la mencionada norma no fue tocada, manteniéndose en los originales términos, dictados para una clase especial: los procesos escritos.

La cuestión clave es que el legislador mantuvo la regla de la apelación conjuntamente subsidiaria, en los mismos términos que para la tramitación de los procesos escritos, mientras que tenía una solución especial y general para los procesos de familia, en materia de audiencia: que la apelación siempre debe ser escrita, separándola de la reposición ${ }^{22}$. En este tema vemos un caso difícil, con dos pretensiones de especialidad, bastante razonables prima facie.

Cualquiera podría decir que la segunda norma, al ser mantenida, es porque el legislador le dio una autorización tácita para regir en los procesos de familia de manera del todo o nada, siendo posterior a la Ley de Tribunales de Familia.

Por otra parte, se puede replicar, con toda razón, que el legislador en la Ley de Tribunales de Familia, creó un modelo muy sistemático para los juicios orales, con reglas sumamente especiales, que tienen que ver con la definición del modelo que se quiere plasmar en la práctica jurídica ${ }^{23}$, y con la cual no tiene relación la norma del inc. $6^{\circ}$ del Art. $4^{\circ}$ LPA. Esto es, se echa mano a una regla de "jerarquía lógica" en la ocurrencia de dos discursos que concurren en el delineamiento de un modelo procesal, y, en particular, de las figuras recursivas en los procesos orales. Mediante este canon de la jerarquía lógica en el discurso, por medio del cual un criterio jurídico domina en un cierto ámbito (el de la configuración indicada), se delinea la pertinencia real de una norma al objetivo temático; en nuestro caso, la configuración de los recursos en los procesos orales. Y luego, con base en estos supuestos, se determina que la especialidad rige a favor de la norma del Art. $67 \mathrm{~N}^{\circ} 3$ LTF. Las razones en concreto para el caso son las siguientes, y tienen que ver con el dominio de casos del principio de oralidad.

La determinación de un principio -como el de oralidad, a que echa mano la teoría 1. no es una mera frase con cualquier contenido, sino que, en la Codificación, va siendo un modelo desarrollado a través de un discurso legislativo

\footnotetext{
${ }^{22}$ Desde el punto de vista del proceso legal, esto responde a un desliz legislativo, y a la usual falta de precisión que, en general, se viene imponiendo como moda de la disciplina legislativa, dejando los "problemas menores" a la solución de los jueces, como si la argumentación jurídica fuera un área del Derecho sumamente desarrollado en todos sus cánones posibles y éstos fuesen de conocimiento general, así como también si a través de la misma se pudiesen solucionar, de manera jurídica, todos los problemas que el legislador deje esparcidos en el derrotero legislativo.

${ }^{23}$ Este cuidado por la sistemática de la normativa del modelo oral, en parte se ve reflejado también, en que el Art. 27 LTF cuida que la remisión a otro cuerpo legislativo de base escrita, como el CPC, se produzca siempre y cuando se respete el modelo procesal oral de la LTF). De esta manera, el Art. 27 LTF manda al intérprete que aplique las disposiciones comunes a todo procedimiento integrándolas a la LTF, "a menos que ellas resulten incompatibles con la naturaleza de los procedimientos que esta ley establece".
} 
y teórico. En particular, este último, para poder hacer uso práctico de aquél, le adjudica un esquema conceptual desarrollado en términos deductivos, pero limitado o controlado desde su base ${ }^{24}$. En la articulación de dicho esquema interviene una serie de factores que lo delinean y limitan, tanto en el discurso legislativo como teórico, por ejemplo, las consideraciones pragmáticas. De ahí que, al decir de M. Cappellettı, un modelo del principio de oralidad, inicialmente configurado más bien en términos reactivos que razonables frente a las graves consecuencias del principio de escrituración, ha ido adoptando una configuración mucho más restrictiva, asumiéndose ciertos beneficios de la escrituración, frente a problemas propios de la oralidad ${ }^{25}$. Ejemplo de ello es la configuración que han ido adquiriendo las leyes sucesivas, respecto de la fase de presentación de las discusiones, de manera originalmente oral, pasando luego a tomar la forma escrita, para efectos de evitar que la contestación oral terminase sorprendiendo al propio demandante en la audiencia, sin posibilidad de preparar el material probatorio para desvirtuar las razones alegadas por el demandado, e infraccionando la garantía de defensa y el debido proceso. En tal sentido, la propia Ley de Tribunales de Familia, en su Art. 10, si bien consagra el principio de oralidad, controla sus efectos, al ordenar que ellos se extenderán sólo hasta donde lo limite la propia Ley de Tribunales de Familia: "Todas las actuaciones procesales serán orales, salvo las excepciones expresamente contenidas en esta ley" (y, en tal sentido, sigue forjando de forma deóntica un eje jerárquico-interpretativo sobre los criterios configuradores del sistema que consagra la LTF).

Limitado el principio de oralidad en su extensión, es necesario revisar cuál es la precisa limitación impuesta en lo que nos interesa, y que, por supuesto, delineará el modelo de proceso oral de familia que queremos, en términos racionalmente controlados.

Justamente, en materia de recursos, el delineamiento del proceso oral y la oralidad vienen dados, en torno al eje de las audiencias orales:

\footnotetext{
${ }^{24}$ S. Cruz Arenhart señala, en el sentido de delineamiento del modelo, que "la doctrina (brasileña e internacional) ha tratado de demostrar que ese principio no se puede resumir, solamente en la predominancia de la forma oral en la práctica de los actos procesales. De hecho, aunque ese elemento sea el más evidente de la caracterización del principio de oralidad, su incidencia debe hacer nacer otras características, que son en general más importantes para la formación de un proceso efectivo, tempestivo y adecuado", agregando luego, que "pensar en la oralidad-inmediación es pensar en un complejo de sub-principios que deben estar presentes cuando se examina un proceso oral". CrUz Arenhart, S. "La Oralidad en la Justicia. El Caso Brasileño", lus et Praxis Año 14 № 2, 2008, p. 128.

${ }^{25}$ Cappelletto, "Valor", cit. nota n. 17, pp. 701 y ss. Un ejemplo de lo dicho es lo que resalta J. Montero AROCA, sobre el enjuiciamiento crítico a la CPO alemana, indicando que el error en que incurrió ésta en 1877, fue que "no previó... sistemas para lograr que las partes fueran a la audiencia con pleno conocimiento de las cuestiones que iban a ser discutidas" (MONTERO, Derecho Jurisdiccional, t. I, Bosch, Barcelona, 1989, p. 526).
} 
i) Tratándose del recurso de reposición, la gravitación de la audiencia lo atrae hacia la oralidad por la centralidad de dicha idea en el modelo. La reposición se presenta oralmente en la audiencia, para ser conocida en ella, lo mismo ocurre si es que dentro de tercero día de notificada la resolución a impugnar, ha de tener lugar una audiencia (precisamente, para que la reposición sea expresada oralmente y sea conocida de esa forma por el juzgado): "Tratándose de una resolución pronunciada en audiencia, se interpondrá y resolverá en el acto" (Art. 67 № 1 LTF). Sólo si la resolución fue dictada fuera de la audiencia y se está fuera del mencionado plazo, entonces se limita o exceptúa la oralidad, a favor de la escrituración.

ii) Sin embargo, el modelo procesal toma otra orientación si se trata del recurso de apelación, y la presentación debe realizarse por escrito. "La apelación, que deberá entablarse por escrito" (Art. 67 № 3 LTF). La ratio legis está en que, a diferencia de la reposición oral, el recurso de apelación siempre va a ser conocido por otro tribunal, por lo tanto, la necesidad de la oralidad inmediata cede, y puede ser evaluada y preparada la apelación para ese otro tribunal con tiempo. De tal guisa, el sistema permite que el litigante no quede atado a las formas argumentativas que se le ocurrieron al abogado en los segundos que toma la discusión en debate oral (muy diferente a la forma de debate en segunda instancia), y, en tal sentido, se evita la tramitación de "apelaciones por defecto", es decir, de aquellas en que el litigante por la premura de la oralidad tiende a apelar, para no perder el recurso, y luego evaluar con calma si es correcto o no $a_{\text {apelar }}^{26}$. Fuera de la audiencia, no concurre ninguno de estos supuestos (salvo que va a conocer otro tribunal), pues ya no se tienen fracciones de segundo para contestar, sino que hay un debido tiempo de emplazamiento, para reponer, por lo que permite preparar con tiempo también la apelación y no se justifica en principio la separación de la apelación de la reposición, constituyendo su conjunción una confluencia del principio de economía procesal.

En tal sentido, de acuerdo a la configuración de la normativa de la LTF, no podríamos sostener que el legislador no previó los casos en que pudiese concurrir una apelación en conjunción potencial con una reposición. Por el contrario, se pronuncia expresamente en el numeral $1^{\circ}$ sobre la posibilidad de una reposición oral en audiencia, y acto seguido, pero separadamente en el numeral $2^{\circ}$, se pronuncia taxativamente de que la apelación deba (y no que pueda) interponerse sólo por escrito para todo caso.

Aquél es el delineamiento de la configuración del sistema recursivo de los procesos orales, en donde, si lo vemos en términos lógicos, poco tiene que ver con dicho delineamiento en términos de objetivos y razones la intervención del

${ }^{26} \mathrm{Vid}$. sobre los antecedentes procesales, infra pp. 15 y 16 y nota 30. 
discurso legislativo de la Ley de Pensiones Alimenticias en su Art. 4 inc. 6. De tal guisa, si la regulación de la LPA, en nuestro tema, es creación ad hoc para los procesos escritos, y su propia aplicación en el contexto de aplicación muestra que lleva a un rompimiento del sistema del juicio oral, entonces podemos afirmar con seguridad, pues que la LPA no está protegida por el principio de especialidad en relación con el modelo oral. Es más, esta última parece adecuarse, en el mejor de los casos, a las razones dadas en la faz escrita de los procesos orales, más que dictaminar normas con sentido para toda y cualesquiera fase del proceso oral. En tal línea, ese viejo inciso final del Art. $5^{\circ}$ LPA, hoy Art. $4^{\circ}$, si es que actualmente tiene una función o una extensión de casos, ella debe venir ajustada a las directrices jerárquico lógicas de la Ley de Tribunales de Familia, quedando con espacio para la solución subsidiaria en los casos de resoluciones dictadas fuera de las audiencias orales, es decir, en la cara escrita del proceso oral de familia.

Adoptar otra solución como la de la primera teoría no tiene mayor razón. No se avizora por qué habría necesidad en este caso y no en otros, por ejemplo, en la relación directa y regular provisoria (en mirada retrospectiva, en el antiguo sistema escrito sí que guardaba coherencia con el régimen general). La solución de la primera teoría rompe con los cánones de uniformidad de la Codificación dentro de la misma materia y nos devuelve al estado crítico previo a las codificaciones del s. XIX, ya que sólo asumimos una regla diferente, sin razón alguna sólo porque aparecen enunciados normativos en una ley que indica una solución general, pero en nuestro caso, sin una dirección legislativa clara de romper o excepcionar el sistema. Esta actuación de la tesis 3.1 trae a la memoria los dichos de uno de nuestros codificadores del Código Civil, R.L. IRARRÁZAVAL, criticando la situación jurídica del antiguo régimen, con "códigos [leyes españolas del s. XIII] que se contradicen el uno al otro, quedando, como casi siempre sucede, indeterminadas las consecuencias de las provisiones correctoras, y en pugna sorda con las consecuencias de las disposiciones reformadas", y agrega que sin hacer una debida armonización de las disposiciones vigentes, "como no cuidaron de hacerlo los legisladores españoles, se introducen en las leyes con cada nueva regla un principio de mutua repulsión y discordia, una fuente inagotable de oscuridades, de interpretaciones más o menos licenciosas, de incertidumbre en los derechos privados, de litigios entre los ciudadanos y perplejidad en los juzgamientos. Esto es, señores, lo que resulta de la sola yuxtaposición de los dos celebrados códigos del siglo 13"27. Para que se entienda

\footnotetext{
${ }^{27}$ IRARRÁZABAL, R. L., "Discurso de Incorporación Solemne en la Universidad de Chile como Miembro de la Facultad de Leyes y Ciencias Políticas", en Guzmán Brito, A, Andrés Bello Codificador, T. II, Ediciones de la Universidad de Chile, Santiago, 1982, p. 249. Sobre la crítica, en general, a estas actitudes de falta de uniformidad en el lus Commune, vid. CoInG, H., "Sobre la Prehistoria de la Codificación: La discusión en torno a la Codificación en los Siglos XVII y XVIII", Revista Chilena de Historia del Derecho № 9, 1983, pp. 249 a 253.
} 
bien, lo que se critica es la generación y existencia de disposiciones no uniformes e incluso contradictorias. Por eso, más allá de la mala técnica legislativa de nuestro legislador, la situación se ve agravada por un deficiente análisis jurídico de la primera teoría, la cual precisamente termina reproduciendo la situación criticada del antiguo régimen.

Además, existe una razón derivada del canon sistemático interpretativo, que apoya la refutación de la tesis de la primacía del Art. 4 inc. 6 LPA, sobre la audiencia oral, resaltando la carencia de pertinencia de dicha norma. Supóngase que se está debatiendo en audiencia el incidente de alimentos provisorios, dictaminando el juez, luego del debate, la resolución ' $X$ '. De acuerdo a la tesis de la primacía del Art. $4^{\circ}$ inc. 6 LPA, entonces debería ser procedente la reposición con apelación en subsidio, sin embargo, esto muestra de forma muy clara la falta de pertinencia de la norma y el error de la tesis. Porque la construcción del proceso oral en audiencia tiene una configuración muy especial, en particular del régimen de los incidentes. Cuando estamos en una audiencia de incidentes importantes como éstos, el juez abre debate escuchando a una parte y luego a la otra, precisamente, por la flexibilidad de la forma oral y la mejor garantía de defensa, no se escucha simplemente una vez a una parte, sino que se permite "replicar" a las partes, tantas veces como el juez lo estime necesario, incluso teniendo éste poderes instructorios muy fuertes para intervenir en el debate, dirigiendo preguntas a una parte o incluso cuestionando ciertos argumentos de la misma, para efectos de mayor precisión y perfección del debate. ¿Es necesario, en tales circunstancias, que sea procedente una reposición, cuando ya se han evacuado todos los argumentos? La respuesta de que sí es necesario porque la ley lo dice (el Art. $4^{\circ}$ inc. 6 LPA), involucra un formalismo tan vacuo, como un desconocimiento y falta de reflexión enorme acerca del desenvolvimiento de los procesos orales en audiencia. De hecho, el legislador, en este caso, con más sabiduría que algunos destinatarios de la ley, ha dispuesto en el Art. 26 LTF que los incidentes deberán resolverse previo debate: "Los incidentes serán promovidos durante el transcurso de las audiencias en que se originen y se resolverán inmediatamente por el tribunal, previo debate $e^{\prime \prime}$ inc. $1^{\circ}$ parte $1^{\mathrm{a}}$ ), pues la forma del debate que se da en la audiencia oral, como hemos visto, realiza la misma actividad y reemplaza lo que es la reposición en los procesos escritos (que son de única palabra ${ }^{28}$. Por lo tanto, ¿es necesaria la reposición?; de acuerdo a lo razonado, es claro que no, por lo que la propia ley estima que no es procedente el recurso de reposición: "Las decisiones que recayeren sobre estos incidentes

\footnotetext{
${ }^{28}$ Recuérdese que en el procedimiento escrito chileno, las discusiones son, en general, de una única oportunidad de palabra, es decir, está la promoción de una cuestión y el traslado, para luego resolver, es decir, no hay opción de replicar (salvo la discusión en el procedimiento ordinario de lato conocimiento, en la fase de discusión), cuestión que viene a paliar la existencia y funcionamiento de la reposición.
} 
no serán susceptibles de recurso alguno" (inc. $1^{\circ}$ parte $3^{\mathrm{a}}$ ). Ahora bien, dado que sabemos que en el choque de la extensión del dominio de casos entre el Art. 26 y el Art. 67 № 2 LTF prima este último -sólo en materia de apelación-, restringiendo la extensión del primero, tratándose de incidentes que pongan término al juicio o hagan imposible su continuación, y en las medidas cautelares, entonces tenemos que, en verdad, en el caso del incidente de los alimentos provisorios, el recurso que no procede es el de reposición ${ }^{29}$, desplazando así lo dispuesto por el Art. $4^{\circ}$ inc. 6 LPA. En tal caso, de acuerdo a las consideraciones ya discutidas como correctas en (2.2) a favor de la doble instancia en casos de especial gravedad para los ciudadanos, como es en los alimentos provisorios, la apelación se deberá interponer directamente (disociándose definitivamente la apelación de la reposición).

Tal solución, además, guarda correlación con el canon histórico interpretativo, como cadena constructiva. La forma que se ha adoptado por el legislador, y que el intérprete quiere desvirtuar sin procedimiento legal, es la del proceso oral modelo en nuestra legislación: la del Código Procesal Penal. Nuestro modelo base dispuso, en conocimiento de todos estos problemas, que el recurso de apelación se interpusiera por escrito como regla generalísima. De esta manera, el Art. 367 CPP dispone: "El recurso de apelación deberá ser interpuesto por escrito"; de ahí que la práctica procesal entendió que la apelación siempre debía interponerse por escrito, como dan cuenta J.D. Correa Selamé, M.I. HorVItZ, J. López, C. Maturana y M. Mosquera, entre otros, para cualquier tipo de resolución que se impugne ${ }^{30}$. El fundamento de dicha decisión político-jurídica, estribó para la Comisión de Constitución, Legislación, Justicia y Reglamento del Senado en lo siguiente: "La Comisión estimó acertada esta norma porque evita

\footnotetext{
${ }^{29}$ Para que el cuadro quede completo, el Art. $67 \mathrm{~N}^{\circ} 1$ LTF establece como regla general la procedencia de la reposición, en audiencia, sin embargo, dado que no toda cuestión sucedida en el proceso es un incidente, que previamente se debata, únicamente en el caso preciso caso de los incidentes se restringe la reposición, constituyendo excepción el Art. 26 al Art. 67 № 1 LTF. Si el legislador de la Codificación fuese más amable con el resto de los ciudadanos de la República, y más preciso en sus normas -y quizá tuviese un mayor conocimiento y control de las normas que dicta-, debiese contemplar claramente la excepcionalidad de ciertas situaciones en el propio articulado, a efectos de una mejor salvaguarda de la certeza jurídica.

${ }^{30}$ Correa Selamé, J.D., Recursos Procesales Penales, Lexis Nexis, Santiago, 2005, p. 81; Horvitz, M. I.; López, J., Derecho Procesal Penal Chileno, T. II, Edit. Jurídica de Chile, Santiago, 2004, p. 376; Maturana, C.; Mosquera, M., Los Recursos Procesales, Edit. Jurídica de Chile, Santiago, 2010, p. 148.

Frente a tal entendimiento de un régimen absoluto, la Ley Procesal Penal 20.253 del año 2008, para romper dicha regla, tuvo que intervenir con una excepción modificando el inc. 2 del Art. 149 CPP, sólo para el caso de apelar la prisión preventiva en ciertos delitos, estableciendo que debe apelarse en audiencia, lo que es oralmente por el principio de misma denominación. Vid. MATURANA, C.; MONTERO López, R., Derecho Procesal Penal, t. I, Legal Publishing, Santiago, 2010, p. 503. De más está decir que la modificación puntualísima, sólo se concretó de manera muy postrera a la recepción y confección operada por el legislador de familia.
} 
la presentación de recursos sin fundamentos y facilita la solución en segunda instancia"131. Precisamente, es en el carácter de absoluto que dicho modelo se adoptó, por completo, para el régimen de los tribunales de familia.

Finalmente, existe un argumento pragmático relacionado con la garantía de defensa procesal. Como bien señaló la Corte de Apelaciones de La Serena existe una antinomia entre las normas en juego difícil de solucionar ${ }^{32}$, y ello bien puede llevar a un litigante a errar en la solución correcta en el ejercicio de su derecho de defensa. Pues bien, la solución en estudio, adoptada por los juzgados de familia, favorece en superior manera el mejor ejercicio del derecho de defensa efectuado mediante el recurso de apelación, ya que de interponerse de manera incorrecta, a través de su presentación verbal en la audiencia respectiva, basta que el tribunal le ordene su interposición en forma, quedando a salvo la posibilidad de apelar, regularmente, por escrito. Sin embargo, con la primera posición, al optar de buena fe por la vía escrita siguiendo la directriz de la LTF, el tribunal debería privarle absolutamente de su derecho a apelar, en algo tan severo como los alimentos provisorios, desamparándose así el ejercicio del derecho de defensa.

En resumen, razones de literalidad, jerarquía lógica, especialidad, estructura de sistema, consistencia lógica, construcción histórica, pragmáticas y la contrarazón de vacuidad, pesan para que tengamos que la norma que prime en esta materia sea la del Art. 67 № 3 LTF, por lo que el recurso de apelación debe ser entablado por escrito en los procesos orales de familia, lo que implica disociar la reposición del recurso de apelación.

2.2. De acuerdo a lo expuesto, hemos visto que en el proceso oral de familia, en el ámbito de las audiencias, se ha disociado definitivamente la relación entre reposición y apelación, pero es necesario revisar más detenidamente otro caso, para ver si la disociación es absoluta o relativa, en nuestro ámbito de estudio.

Ya está bastante clara en el ejemplo antes visto, la disociación definitiva entre reposición y apelación operada en los casos de incidentes de alimentos provisorios ventilados en audiencia. Sin embargo, ¿qué ocurre cuando el incidente de alimentos provisorios es resuelto por escrito, incluso la oposición, pero la reposición es interpuesta en la audiencia?, ¿en qué posición quedan los litigantes?

La procedencia de la reposición no tiene las restricciones anteriormente expuestas. Ello porque se trata de un incidente cuya disputa se ha dado, has-

\footnotetext{
${ }^{31}$ Maturana (Coord.), Reforma Procesal Penal, T. III, Edit. Jurídica de Chile, Santiago, 2003, p. 70. M.I. HORVITZ y J. LÓPEZ ratifican el aserto señalando: "El recurso debe interponerse por escrito, lo que obviamente excluye la posibilidad de que se utilice como una forma de reacción inmediata frente a una resolución dictada en el transcurso de una audiencia" (HORVITZ; LóPEZ, Derecho, cit. nota n. 30, ibíd.).

${ }^{32}$ Vid. supra nota 1.
} 
ta el momento, de manera escrita. De acuerdo al Art. 26 inc. 2 LTF, pueden presentarse incidentes por escrito, y pueden ser resueltos de plano, lo que es concordante con la disposición de inc. $1^{\circ}$ del Art. $4^{\circ}$ LPA, en orden a que pueden pedirse alimentos provisorios en la propia demanda (un incidente in limine litis), pudiendo el juez resolver de plano (que es la variante que nos interesa). En este caso, el legislador alzó la prohibición de recursividad tanto en el inc. 2 y 3 del Art. 26 LTF, y sí dispuso de manera complementaria, en el Art. 67 № 1 LTF, la procedencia de la reposición en general: "La solicitud de reposición deberá presentarse dentro de tercero día de notificada la resolución, a menos que dentro de dicho término tenga lugar una audiencia, en cuyo caso deberá interponerse y resolverse durante la misma". En tal sentido, la Ley de Tribunales de Familia, por ahora, es más que suficiente para justificar la solución de recurrir de reposición; y prima ésta al disponer que, estando dispuesta, dentro del plazo de tres días para reponer, la realización de la audiencia, entonces ella debe interponerse verbalmente y no por escrito. ¿Pero qué sucede con el recurso de apelación?

El recurso de apelación al estar inserta, por la variación de las circunstancias, en una situación fáctica estricta de oralidad, en la audiencia, debe ella ser presentada por escrito, según hemos visto correctamente. Pero ¿debe, necesariamente, proceder luego de la reposición? y ¿necesariamente de la parte litigante que repone?

Respecto a si la reposición debe ser precedente de manera necesaria al recurso de apelación, por parte del perdidoso de la oposición a los alimentos provisorios, debe responderse afirmativamente, aunque ello no es extremadamente claro normativamente. Como vimos, la idea de la reposición en los procedimientos escritos, no sólo tiende a hacer ver los errores propios del tribunal, sino que dado que el debate es de "una palabra" por cada parte, la reposición busca dar la oportunidad de replicar a la parte perdidosa, respecto de pretensiones argumentativas falaces de la contraria que movieron al tribunal a resolver de manera perjudicial a sus intereses. Trasladado esto al proceso oral en esta situación de debate mixto (en parte escrita y en parte oral), y tratando de maximizar la concentración del proceso y de economía, de tal manera que sea el juez oral de familia quien deba resolver la incidencia, tratando de agotar la discusión allí y de evitar su desgaje en otra instancia ${ }^{33}$, se permite entablar la reposición en la audiencia ventilando los argumentos oralmente, como indica el

\footnotetext{
${ }^{33}$ En Brasil, la concentración se manifiesta de manera mucho más fuerte, en el subprincipio de la "inapelabilidad separada de las interlocutorias". S. Cruz Arenhart, señala que "un sistema procesal que se pretenda, de hecho, oral e inmediato, no puede tolerar que las partes tengan la prerrogativa de apelar, en cualquier momento... de cualquier especie de decisión" (es decir, no apelación en general, aunque no necesariamente en particular, alguna especial), y agrega que con "el objetivo de que se pueda desarrollar la oralidad en toda su extensión, es fundamental que las decisiones interlocutorias
} 
propio Art. $67 \mathrm{~N}^{\circ} 1 \mathrm{LTF}^{34}$. Por tanto, sí es un requisito que se entable la reposición antes de un recurso de apelación, pero por consecuencia deóntica del principio de concentración propio del proceso oral y de economía procesal.

Tomando aquel último enunciado como premisa en la construcción del argumento, respecto a responder a la pregunta por si el perdidoso de la oposición de los alimentos debe entablar la reposición para poder entablar el recurso de reposición, tenemos que concluir que sí necesariamente debe hacerlo.

¿Qué sucede con el ganador de la oposición a los alimentos provisorios, en qué posición queda en relación con la oposición? Previamente, debo aclarar que el ganador puede ser el demandado o el demandante. Obviamente, como ganador completo de la oposición carece de un requisito básico para recurrir: del interés procesal, por falta de agravio. Por ende, no puede recurrir de reposición; de hecho, no tiene sentido racional que lo haga, en principio ${ }^{35}$. Quien tiene la legitimación para reponer es el perdidoso, es decir, su parte contraria (no obstante que ambos tengan potencialmente el poder de reponer, por disposición legal del Art. $67 \mathrm{~N}^{\circ} 1 \mathrm{LTF}$ ). Pero ahora debemos reflexionar más precisamente sobre ¿qué sucede si el ganador de la oposición pierde la reposición oral, tiene el poder de apelar?

Aquí nuevamente podemos dar dos respuestas formalistas, pero ambas totalmente vacuas, y una tercera jurídicamente fundada.

i. La primera respuesta formalista dice, puede apelar pero debe reponer de la resolución que se pronunció de la reposición de la contraria. Ello, porque es la única forma de hacer procedente el recurso de apelación.

Esta primera tesis es bastante insuficiente, por dos razones. Estamos hablando de una reposición de una reposición. Se trata de un recurso que ya fue utilizado y consumido por una de las partes; es más, incluso hay agotamiento del mismo, al pronunciarse el juzgado sobre la petición de la contraria. La nueva reposición sólo volvería a plantear la misma cuestión, entre las mismas partes sobre la misma materia jurídica. Pero además, tratándose de un incidente

solamente puedan ser apeladas al final del procedimiento, juntamente con la sentencia final" (CrUz, "La Oralidad", cit. nota n. 24, pp. 140 y 141).

${ }^{34}$ Consecuencia de la idea de economía procesal se encuentra la idea de conjuntar el recurso de apelación a la reposición, como en el Art. 188 CPC y el Art. $4^{\circ}$ inc. $6^{\circ}$ LPA, de tal manera de dar la oportunidad de ventilar las réplicas a los argumentos de la contraria y a los del juez que conoce del asunto, para efectos de que el litigante perdidoso, generando la opción de que éste pudiese quedar tranquilo con la respuesta del tribunal a los argumentos de su reposición, sin tener que cargar al órgano ad quem de la revisión del asunto. El principio de concentración, por supuesto no es pertinente en los procesos escritos.

${ }^{35}$ Personalmente, me ha tocado ver un solo y extraño caso, en donde el ganador completo sí tenía un interés legítimo en que se revocara parte de la resolución que lo daba por ganador, pero se trataba de otra materia en extremo diversa. 
como el de los alimentos provisorios, en donde la reposición oral es una parte de aquél, ésta se somete a las reglas de los incidentes del Art. 26 inc. 1 parte $3^{\text {a }}$ LTF, es decir, debe ser conocida con debate oral, lo que nos vuelve al tema de que los incidentes, aun en lo tocante en materia de audiencia, no pueden ser recurridos de reposición, precisamente porque el debate oral ya se produjo (que precisamente reemplaza a la reposición).

ii. La segunda respuesta formalista dice que no puede presentarse el recurso de apelación. Porque, fundado en las dos críticas antes expuestas, el inicial ganador y final perdedor, no puede interponer la reposición, por lo que no puede cumplir con el requisito de la precedencia de la reposición, que mandata el principio de concentración en conjunción con el Art. 67 LTF.

Esta segunda tesis, bien poco se esfuerza por lograr una construcción argumentativa razonable. Porque ya se ha visto que la función que cumple la reposición, es reemplazada en la audiencia oral por el debate en materia de incidentes, según lo razonado en torno al inc. $1^{\circ}$ del Art. 26 LTF. Pero además, esta tesis termina yendo en contra de la garantía constitucional de la igual protección de la ley, del Art. $19 \mathrm{~N}^{\circ} 3$ inc. $1^{\circ} \mathrm{CPR}$ ("la Constitución asegura a todas las personas... La igual protección de la ley en el ejercicio de sus derechos"), en su variante de igualdad de armas, es decir, protege a los ciudadanos para el ejercicio de sus derechos disponiendo a cada parte los mismos instrumentos de defensa, según su posición procesal. En efecto, dado que ambas partes litigantes, por regla constitucional, tienen una igual protección de ley en materia de medios y recursos de defensa, a ambas se les dispensa jurídicamente del recurso de apelación en igualdad de condiciones, para recurrir en contra de las sentencias que les aparezcan como gravosas a sus intereses. El tema es que por una cuestión de mera combinación de circunstancias, en principio inmanejable a priori, un litigante estaría perdiendo la opción de apelar, mientras que el otro sí mantendría su arma, su recurso, produciéndose de tal manera la desigualdad en las posiciones por un asunto de azar. $Y$ señalamos que es formalista, porque en definitiva, es negligente a la hora de analizar la razón de la especial estructuración de la tramitación de este proceso, pues si la reposición era procedente, lo era, justamente, por la idea de concentración y economía, y sabemos que la forma de debate oral reemplaza la necesidad de la reposición, porque permite ventilar -a la manera de la reposición- la argumentación de las partes, satisfaciéndose así, la exigencia de concentración y economía, pues permite a la recurrida de reposición evacuar sus argumentos en más de una ocasión en el debate oral, cumpliéndose así una finalidad de la reposición, en relación con la concentración y economía. Cerrado el círculo argumentativo, no queda razón de ver de por qué exigir reposición cuando hemos cumplido la exigencia y en parte finalidad de la misma. 
iii. La tercera opción ya viene delineada por lo expuesto anteriormente, si el principio de concentración y economía fundan la exigencia de reposición previa al recurso de apelación y parte de la finalidad, en el sentido indicado se ha cumplido mediante el canon de reemplazo del debate oral en los incidentes, y tenemos una disposición constitucional como la del Art. $19 \mathrm{~N}^{\circ} 3$ inc. $1^{\circ}$, que contempla igualdad de armas en la protección del ejercicio de los derechos, siendo el recurso de apelación una de ellas. Y observando la razón negativa de lo absurdo de pedirle al ganador de la oposición que recurra de reposición de la misma, precisamente por ser el ganador, es que se concluye que, jurídicamente, el perdedor de la reposición de los alimentos provisorios, sólo si ha participado del debate, está habilitado para interponer recurso de apelación por escrito, según el Art. $67 \mathrm{~N}^{\circ}$ s. 2 y 3 LTF, disociada de una propia reposición.

\section{SíNTESIS FINAL}

Como cuestión general, el ordenamiento jurídico de los tribunales de familia presenta una disociación, en materia oral, de la apelación respecto a la reposición, por lo mismo, vemos las siguientes conclusiones:

1. Respecto a la cuestión de la procedencia del recurso de apelación relativo a los alimentos provisorios dictados en audiencia, la respuesta es afirmativa, en virtud del Art. $67 \mathrm{~N}^{\circ} 2$ LTF.

2. En lo relativo al problema de la forma de procedencia del recurso de apelación en contra de la resolución de incidentes de alimentos provisorios decretados en audiencia: procede que se interponga la apelación por escrito, de acuerdo al Art. 67 № 3 LTF.

3. Tratándose de alimentos provisorios decretados por escrito, sin audiencia, haciendo uso de la oposición, la apelación deberá interponerse de manera subsidiaria a la reposición, por escrito, según las reglas generales.

4. Si los alimentos provisorios fueron decretados por escrito, sin audiencia, habiéndose utilizado la oposición, pero estando el plazo para recurrir consumido dentro del tiempo decretado para la audiencia, la reposición deberá entablarse oralmente y la apelación por escrito, a virtud del Art. 67 No 3 LTF.

4.1. Quien perdió la oposición, debe interponer la apelación necesariamente luego de la reposición, si es que tiene interés procesal en ello.

4.2. Quien ganó la oposición, pero perdió la reposición, puede interponer directamente la apelación.

\section{BiBLIOGRAFÍA}

Anabalón Sanderson, C., Tratado Práctico de Derecho Procesal Civil Chileno, Ediciones de la Universidad de Chile, Santiago, 1946. 
Bоввıо, N., "Sobre los Criterios para Resolver Antinomias", en Contribución a la Teoría del Derecho, Traducción de Ruiz Miguel, A., Edit. Debate, 1990, Madrid.

Calamandrel, P., Introducción al Estudio Sistemático de las Providencias Cautelares, Traducción de Ayerra, Librería El Foro, B. Aires, 1996.

Cappellettı, M., "Valor Actual del Principio de Oralidad", Revista de la Facultad de Derecho de México № 37, 1960.

Carneluttı, F., Sistema de Derecho Procesal Civil, T. I, Traducción de Alcalá Zamora, UTEHA, B. Aires, 1944. Instituciones del Proceso Civil, Traducción de Sentís, V. I, EJEA, B. Aires, 1959.

ColnG, H., "Sobre la Prehistoria de la Codificación: La discusión en torno a la Codificación en los Siglos XVII y XVIII", Revista Chilena de Historia del Derecho No 9, 1983.

Correa Selamé, J.D., Recursos Procesales Penales, Lexis Nexis, Santiago, 2005

Cruz Arenhart, S., "La Oralidad en la Justicia. El Caso Brasileño", lus et Praxis Año 14, № 2, 2008.

Gandulfo, E., "Sobre Preclusiones Procesales en el Derecho Chileno en Tiempo de Reformas", lus et Praxis Año 15, № 1, 2009.

Horvitz; M. I.; López, J., Derecho Procesal Penal Chileno, T. II, Edit. Jurídica de Chile, Santiago, 2004.

IRARRÁZABAL, R. L., "Discurso de Incorporación Solemne en la Universidad de Chile como Miembro de la Facultad de Leyes y Ciencias Políticas", en Guzmán Brito, A., Andrés Bello Codificador, T. II, Ediciones de la Universidad de Chile, Santiago, 1982.

Liebman, E.T., Manual de Derecho Procesal Civil, Traducción Sentís, S., Ejea, B. Aires, 1980.

Marín, J.C., Las Medidas Cautelares en el Proceso Civil Chileno, Edit. Jurídica de Chile, Santiago, 2004.

Maturana, C., Reforma Procesal Penal, T. III, Edit. Jurídica de Chile, Santiago.

Maturana, C.; Montero López, R., Derecho Procesal Penal, T. I, Legal Publishing, Santiago, 2010.

Maturana, C.; Mosquera, M., Los Recursos Procesales, Edit. Jurídica de Chile, Santiago, 2010.

Montero Aroca, J., Derecho Jurisdiccional, T. I, Bosch, Barcelona, 1989.

, "Síntesis de Derecho Procesal Civil Español", Boletín Mexicano de Derecho Comparado № 89, 1997.

Romero, A., Curso de Derecho Procesal Civil, T. I, Edit. Jurídica de Chile, Santiago, 2006. 
Rosenberg, L., Derecho Procesal Civil, T. I, Traducción de A. Romera, E. Carlos, E Krotoschint, EJEA, Buenos Aires, 1955.

SaAvedra Gallo, P., "Reflexiones sobre los Incidentes en el Proceso Declarativo", Boletín de la Facultad de Derecho de la UNED № 1, 1992.

SalAs VIvaldi, J., Los Incidentes y en Especial el de la Nulidad Procesal, Editorial Jurídica de Chile, Santiago, 1989. 
